Manuscript submitted to Journal of Catalysis

Date: June 23, 2016

Selective hydrogenation of biomass-derived 2(5H)-furanone over

Pt-Ni and Pt-Co bimetallic catalysts: From model surfaces to

\title{
supported catalysts
}

Xiaodan $\mathrm{Li}^{\mathrm{a}}$, Weiming Wan ${ }^{\mathrm{b}}$, Shyam Kattel ${ }^{\mathrm{c}}$, Jingguang G. Chen* ${ }^{\mathrm{b}, \mathrm{c}}$, Tiefeng Wang*a 


\section{Abstract}

The selective hydrogenation of biomass-derived $2(5 \mathrm{H})$-furanone to $\gamma$-butyrolactone (GBL) was studied over Pt-Ni and Pt-Co bimetallic model surfaces and supported catalysts. The reactions of $2(5 \mathrm{H})$-furanone were investigated on $\mathrm{Ni} / \mathrm{Pt}(111)$ and $\mathrm{Co} / \mathrm{Pt}(111)$ bimetallic surfaces using temperature-programmed desorption (TPD), revealing that the Ni-terminated bimetallic Ni-Pt-Pt(111) surface was more active and selective to produce GBL. Parallel density functional theory (DFT) calculations also confirmed the higher hydrogenation activity on Ni-Pt-Pt(111) due to bimetallic effect. The promising results on model surfaces were extended to $\mathrm{SiO}_{2}$-supported catalysts. The hydrogenation activity in terms of the initial turnover frequency (TOF) followed the trend of Pt-Ni $>\mathrm{Pt}-\mathrm{Co}>\mathrm{Pt}>\mathrm{Ni}>\mathrm{Co}$, where the TOF over Pt-Ni was almost twice higher than that over Pt. With the excellent correlation between model surfaces and supported catalysts, the Pt-Ni bimetallic catalyst was identified as a promising option for the selective hydrogenation of 2(5H)-furanone to GBL.

Keywords: 2(5H)-Furanone; $\gamma$-Butyrolactone; Selective hydrogenation; Ni/Pt(111) surfaces; $\mathrm{Co} / \mathrm{Pt}(111)$ surfaces; Bimetallic catalysts 


\section{Introduction}

Biomass-derived molecules can serve as a renewable source for the sustainable production of fuels and chemicals [1,2]. During the past decades, novel synthetic methods and catalytic processes have been developed for the synthesis of $\mathrm{C}_{4}$ biomass-derived molecules such as succinic acid, maleic acid and 2(5H)-furanone [3-5]. For example, many efforts have focused on the production of $2(5 \mathrm{H})$-furanone by oxidation of furfural, which can be easily produced from lignocellulose [6], and a reasonable yield of $2(5 \mathrm{H})$-furanone over $60 \%$ was achieved in our recent work [7]. However, the potential for further conversion of $2(5 \mathrm{H})$-furanone to high value-added chemicals remains largely unexplored [8]. In view of the chemical structure, $2(5 \mathrm{H})$-furanone has only one more additional $\mathrm{C}=\mathrm{C}$ bond than $\gamma$-butyrolactone $(\mathrm{GBL})$. Thus it is a promising platform compound to produce GBL and 1,4-butanediol (BDO), which can be widely used as monomers, solvents and perfumes $[9,10]$. The selective hydrogenation of the $\mathrm{C}=\mathrm{C}$ bond of $2(5 \mathrm{H})$-furanone allows the design of an optimum reaction pathway with high atom economy starting from a renewable oxygenate to the target product, GBL.

In our previous work, the selective hydrogenation of $2(5 \mathrm{H})$-furanone to GBL was studied over a series of $\mathrm{SiO}_{2}$-supported Group VIII monometallic catalysts [11]. It showed that $\mathrm{Pd}$ and $\mathrm{Rh}$ exhibited better catalytic performances than other monometallic catalysts such as $\mathrm{Pt}, \mathrm{Ru}, \mathrm{Ni}, \mathrm{Co}$ and $\mathrm{Cu}$. However, further studies are needed to understand the descriptors that control the hydrogenation activity and selectivity. The Pt-based bimetallic catalysts have shown very different electronic and chemical properties compared with their parent metals [2,12-14]. Enhancing the activity and/or selectivity of the Pt catalysts by adding a second metal has been verified for the selective hydrogenation of $\mathrm{C}=\mathrm{C}$ bond in many reactions. For example, Lu et al. [15] studied the 
selective hydrogenation of cyclohexene over $\gamma-\mathrm{Al}_{2} \mathrm{O}_{3}$ supported Pt, Pt-Ni and Pt-Co catalysts, with the rate constants of $1.7,27$ and $21 \mathrm{~min}^{-1}$ for $\mathrm{Pt} / \gamma-\mathrm{Al}_{2} \mathrm{O}_{3}, \mathrm{Pt}-\mathrm{Ni} / \gamma-\mathrm{Al}_{2} \mathrm{O}_{3}$ and $\mathrm{Pt}-\mathrm{Co} / \gamma-\mathrm{Al}_{2} \mathrm{O}_{3}$, respectively. Zheng et al. [16] reported the controlled hydrogenation of $\mathrm{C}=\mathrm{C}$ and $\mathrm{C}=\mathrm{O}$ bonds in cinnamaldehyde over $\mathrm{SiO}_{2}$-supported Pt-Co and Pt-Cu bimetallic catalysts. The results indicated that both catalysts were more active than the monometallic catalysts, and that Pt-Co enhanced the hydrogenation of $\mathrm{C}=\mathrm{O}$ bond while $\mathrm{Pt}-\mathrm{Cu}$ preferred the hydrogenation of $\mathrm{C}=\mathrm{C}$ bond. Li et al. [17] showed that for the hydrogenation of maleic anhydride, the addition of Ni to Pt increased both the hydrogenation activity and selectivity to succinic acid, and the $\mathrm{Pt}-\mathrm{Ni} / \mathrm{Al}_{2} \mathrm{O}_{3}$ bimetallic catalyst was more active and selective than $\mathrm{Pd} / \mathrm{Al}_{2} \mathrm{O}_{3}$ and $\mathrm{RhCl}_{2}(\mathrm{TPP})_{3}[18,19]$. Overall, most of the Pt-based bimetallic catalysts reported in the literature exhibited improved hydrogenation activity and different selectivity compared with the corresponding monometallic catalysts. However, there have been no studies on the utilization of Pt-based bimetallic catalysts for $2(5 \mathrm{H})$-furanone hydrogenation.

As a highly functionalized $\mathrm{C}_{4}$ molecule, $2(5 \mathrm{H})$-furanone has two unsaturated bonds, namely the $\mathrm{C}=\mathrm{C}$ and $\mathrm{C}=\mathrm{O}$ bonds, and it also contains two $\mathrm{C}-\mathrm{O}$ bonds within the ring. As a result, different adsorption geometries and strengths of $2(5 \mathrm{H})$-furanone can exist on the catalyst surface, which may favor different reaction pathways, such as the selective hydrogenation of the $\mathrm{C}=\mathrm{C}$ or $\mathrm{C}=\mathrm{O}$ bond, and the ring opening via $\mathrm{C}-\mathrm{O}$ bond scission. In the past decade, surface science experiments and density functional theory (DFT) calculations have been used to study the adsorption geometry and reaction pathways of biomass-derivatives or their probe molecules on single crystal metal surfaces [13,20-23]. Vorotnikov et al. [24] preformed DFT calculations to investigate the reaction mechanisms and reaction barriers for the hydrogenation of furfural to 2-methyfuran, furfuryl 
alcohol and furan on $\operatorname{Pd}(111)$. Myint et al. $[25,26]$ compared the adsorption and reaction pathways of propanal and 1-propanol on $\mathrm{Ni} / \mathrm{Fe}(111), \mathrm{Cu} / \mathrm{Ni}(111)$ and $\mathrm{Ni} / \mathrm{Mo}(110)$ bimetallic surfaces using DFT calculations and temperature-programmed desorption (TPD). Similar theoretical and experimental studies have been carried out to study the hydrogenation of $\mathrm{C}=\mathrm{C}$ bonds in a variety of molecules over the 3d/Pt(111) model surfaces and supported Pt-3d bimetallic catalysts [27-29]. These surface science experiments and DFT calculations provide insights into the reaction mechanisms and help the design of efficient hydrogenation catalysts.

This work reports the utilization of Pt-Ni and Pt-Co bimetallic catalysts for 2(5H)-furanone hydrogenation. DFT calculations and surface science experiments under ultrahigh vacuum (UHV) conditions were performed on the $\mathrm{Ni} / \mathrm{Pt}(111)$ and $\mathrm{Co} / \mathrm{Pt}(111)$ bimetallic surfaces as well as $\mathrm{Pt}(111)$, $\mathrm{Ni}(111)$ and $\mathrm{Co}(0001)$ monometallic surfaces to study the effect of bimetallic formation on the adsorption and hydrogenation of $2(5 \mathrm{H})$-furanone. In parallel, $\mathrm{SiO}_{2}$-supported $\mathrm{Pt}-\mathrm{Ni}$ and $\mathrm{Pt}-\mathrm{Co}$ bimetallic catalysts and the corresponding monometallic catalysts were synthesized, characterized and evaluated for the liquid-phase hydrogenation of $2(5 \mathrm{H})$-furanone to GBL. The combination of theoretical and experimental studies provided a fundamental understanding of $2(5 \mathrm{H})$-furanone hydrogenation over bimetallic catalysts.

\section{Theoretical and experimental methods}

\subsection{Density functional theory (DFT) calculations}

All DFT calculations were performed using the Vienna Ab-Initio Simulation Package (VASP) code [30-33]. A plane wave cut-off energy of $400 \mathrm{eV}$ and a $3 \times 3 \times 1$ Monkhorst-Pack grid were used for total energy calculations. The interactions between the electrons and nuclei were treated with all electron like projector augmented wave (PAW) potentials with the generalized gradient 
approximation (GGA) using the PW91 functional [34,35].

The Pt(111), Ni(111) and Co(0001) monometallic surfaces and Pt-Ni-Pt(111), Ni-Pt-Pt(111), Pt-Co-Pt(111) and Co-Pt-Pt(111) bimetallic surfaces were modeled using four layers of $3 \times 3$ surface slabs. The $\mathrm{Pt}(111)$ surface was modified by replacing the subsurface $\left(2^{\text {nd }}\right.$ layer $) \mathrm{Pt}$ atoms with $\mathrm{Ni}$ and $\mathrm{Co}$ atoms to model the Pt-Ni-Pt(111) and Pt-Co-Pt(111) subsurface structures, respectively. The Ni-Pt-Pt(111) and Co-Pt-Pt(111) surfaces were modeled by replacing the top Pt atoms of the $\mathrm{Pt}(111)$ surface with $\mathrm{Ni}$ and Co atoms, respectively. A vacuum layer of $\sim 14 \AA$ thick was added in the slab cell along the direction perpendicular to the surface in order to minimize the artificial interactions between the surface and its periodic images. During geometry optimization, atoms in the top two layers were allowed to relax while atoms in the bottom two layers were fixed until the Hellman-Feynman force on each ion was smaller than $0.01 \mathrm{eV} / \mathrm{A}$. The binding energy (BE) of an adsorbate was calculated as:

$$
\mathrm{BE}(\text { adsorbate })=E(\text { slab }+ \text { adsorbate })-E(\text { slab })-E(\text { adsorbate })
$$

where $E($ slab + adsorbate), $E($ slab $)$ and $E$ (adsorbate) are the total energy of slab with adsorbate, energy of clean slab and energy of adsorbate in the gas phase, respectively. The transition state of a chemical reaction in this work was located using the climbing image nudged elastic band (CI-NEB) method [36]. The activation energy $\left(E_{\mathrm{a}}\right)$ of a chemical reaction is defined as the energy difference between the initial and transition states while the reaction energy $(\Delta \mathrm{E})$ is defined as the energy difference between the initial and final states.

\subsection{Temperature-programmed desorption (TPD) experiments}

The TPD experiments were performed in a UHV chamber with a base pressure of $1 \times 10^{-10}$ Torr, equipped with an Auger electron spectroscopy (AES), a mass spectrometer, a sputter gun and 
the Ni (or Co) metal source, as described previously [37]. A Pt(111) single crystal (Princeton Scientific, 99.99\%, $2 \mathrm{~mm}$ thick and $10 \mathrm{~mm}$ in diameter) was placed in the UHV chamber by directly spot-welding to two tantalum posts, allowing resistive heating and cooling with liquid nitrogen. A chromel-alumel K type thermocouple was welded to the back of the $\operatorname{Pt}(111)$ sample for temperature measurement. The $\operatorname{Pt}(111)$ surface was cleaned using sputtering-annealing cycles. The $\mathrm{Ni} / \mathrm{Pt}(111)$ and $\mathrm{Co} / \mathrm{Pt}(111)$ bimetallic surfaces were prepared by controlling the current of $\mathrm{Ni}$ or $\mathrm{Co}$ metal source, the temperature of $\operatorname{Pt}(111)$ surface and the deposition time. In this work, the Ni-terminated and Co-terminated bimetallic surfaces, Ni-Pt-Pt(111) and Co-Pt-Pt(111), were prepared by depositing a monolayer (ML) coverage of Ni and Co, respectively, with the $\mathrm{Pt}(111)$ substrate held at $300 \mathrm{~K}$. The Pt-terminated bimetallic surfaces, Pt-Ni-Pt(111) and Pt-Co-Pt(111), were obtained by deposition with the Pt (111) substrate held at $600 \mathrm{~K}$. The bimetallic surface composition was characterized using AES as described previously [38]. Longer deposition time generated surfaces composed of a $\mathrm{Ni}$ (or Co) film of increasing thickness on $\mathrm{Pt}(111$ ), designated as thick $\mathrm{Ni}$ (or $\mathrm{Co}$ ), which approximated the structure and reactivity of $\mathrm{Ni}(111)$ (or $\mathrm{Co}(0001)$ ) [39].

2(5H)-Furanone (Sigma Aldrich, 98\%) and GBL (Sigma Aldrich, 99\%) were transferred into separate glass sample cylinders and purified using freeze-pump-thaw cycles. All other gases including hydrogen and neon were of research purity and used without further purification. The reagents were dosed into the UHV system through a stainless steel dosing tube and the purity was verified before experiments using mass spectrometry. During the TPD measurements, the crystal surface with adsorbate was heated with a linear rate of $3 \mathrm{~K} \cdot \mathrm{s}^{-1}$ and the products desorbing from the crystal surface were monitored using a quadrupole mass spectrometer.

\subsection{Preparation of supported catalysts}


The supported Pt-Ni and Pt-Co bimetallic catalysts were prepared by incipient wetness co-impregnation to obtain the greatest extent of bimetallic bond formation, as described previously [40]. The corresponding $\mathrm{Pt}, \mathrm{Ni}$ and Co monometallic catalysts were also synthesized to serve as control samples. The metal loading for each catalyst was listed in Table 1. Typically, the respective metal precursors $\left(\mathrm{H}_{2} \mathrm{PtCl}_{6} \cdot 6 \mathrm{H}_{2} \mathrm{O}, \mathrm{Ni}\left(\mathrm{NO}_{3}\right)_{2} \cdot 6 \mathrm{H}_{2} \mathrm{O}, \mathrm{Co}\left(\mathrm{NO}_{3}\right)_{2} \cdot 6 \mathrm{H}_{2} \mathrm{O}\right.$, Alfa Aesar) were dissolved in a suitable amount of distilled water just sufficient to fill the pores of the $\mathrm{SiO}_{2}$ support $\left(140 \mathrm{~m}^{2} \cdot \mathrm{g}^{-1}\right.$, Alfa Aesar), which was then dropwise added to the support. The impregnated samples were treated with ultrasound for $1 \mathrm{~h}$ to facilitate the metal dispersion. The catalysts were then dried at $353 \mathrm{~K}$ for $10 \mathrm{~h}$ and calcined in air at $723 \mathrm{~K}$ for $3 \mathrm{~h}$.

\subsection{Characterization of supported catalysts}

The CO chemisorption measurements were performed on a Quantachrome ChemBET Pulsar TPR/TPD instrument equipped with a thermal conductivity detector (TCD) to estimate the number of metal active sites for the supported catalysts. For each test, $200 \mathrm{mg}$ of catalyst was loaded into a U-tube quartz reactor and reduced in $10 \% \mathrm{H}_{2} / \mathrm{He}$ at $723 \mathrm{~K}$ for $1 \mathrm{~h}$. The sample was then purged with pure $\mathrm{He}$ at $723 \mathrm{~K}$ for $30 \mathrm{~min}$ to remove the absorbed $\mathrm{H}_{2}$ on the catalyst surface and cooled to room temperature. Subsequently, $\mathrm{CO}$ pulses were injected consecutively until the effluent area of the pulses was constant. The hydrogen temperature-programmed reduction $\left(\mathrm{H}_{2}-\mathrm{TPR}\right)$ measurements were carried out on the same apparatus to test the reducibility of the supported catalysts. The sample $(\sim 200 \mathrm{mg})$ was heated from room temperature to $1073 \mathrm{~K}$ at a ramp of 10 $\mathrm{K} \cdot \mathrm{min}^{-1}$ with a $5 \% \mathrm{H}_{2} / \mathrm{Ar}$ stream of $100 \mathrm{~mL} \cdot \mathrm{min}^{-1}$.

Transmission electron microscopy (TEM) images were taken on a JEM2010 transmission electron microscope at $200 \mathrm{kV}$. To prepare the TEM samples, the catalysts were first reduced in 
hydrogen at $723 \mathrm{~K}$ for $3 \mathrm{~h}$, which were then grinded into fine powders and suspended in acetone with a concentration of $10 \mathrm{mg} \cdot \mathrm{mL}^{-1}$. Droplets of the suspension were deposited onto the carbon coated copper grid and dried overnight at room temperature. For each catalyst, over 100 particles were collected to analyze the metal particle size distribution and to calculate the average metal particle size.

\subsection{Catalytic evaluation of supported catalysts}

The supported catalysts were evaluated for the liquid-phase hydrogenation of $2(5 \mathrm{H})$-furanone in a stainless steel autoclave (Weihai Chemical Machinery Co., Ltd., $300 \mathrm{~mL}$ ). 2(5H)-Furanone was synthesized by furfural oxidation and purified by vacuum distillation as described in a previous publication [11]. The purity of the synthesized $2(5 \mathrm{H})$-furanone was in the range of 95-98\%, which was determined with a gas chromatography (GC) by comparing the purified 2(5H)-furanone with the standard sample (98.0\%, Alfa Aesar). In a typical experiment, the catalyst was reduced in $\mathrm{H}_{2}$ at $723 \mathrm{~K}$ for $3 \mathrm{~h}$ and protected in $\mathrm{N}_{2}$ in the reduction tube prior to the reaction. Then $6.0 \mathrm{~g}$ of $2(5 \mathrm{H})$-furanone, $100 \mathrm{~mL}$ of methanol (99.5\%, Beijing Chemical Works) as the solvent, and $0.15 \mathrm{~g}$ of the reduced catalyst, were loaded into the reactor, which was sealed and purged with $\mathrm{N}_{2}$ immediately and then heated to $353 \mathrm{~K}$ under $0.5 \mathrm{MPa} \mathrm{H}_{2}$. When the reaction temperature reached at the specified value (i.e. $353 \mathrm{~K}$ ), the reactor was pressurized to $3.5 \mathrm{MPa}$ within $5 \mathrm{~min}$. The time when the pressure achieved at $3.5 \mathrm{MPa}$ was considered as the zero of the reaction time. The stirring speed was set at $800 \mathrm{r} \cdot \mathrm{min}^{-1}$ and the $\mathrm{H}_{2}$ gas flow rate was set at 180 $\mathrm{mL} \cdot \mathrm{min}^{-1}$ to reduce the gas-liquid mass transfer resistance. The products were sampled and analyzed using a GC 7900 II (Techcomp Instrument Company) equipped with a super-wax capillary column $(30 \mathrm{~m} \times 0.25 \mathrm{~mm} \times 0.5 \mu \mathrm{m})$ and a flame ionization detector (FID). The 
conversion of $2(5 \mathrm{H})$-furanone and selectivity to GBL were calculated as:

$$
\begin{gathered}
\text { Conversion of } 2(5 \mathrm{H}) \text {-furanone }(\%)=\left(n_{\mathrm{F}, 0}-n_{\mathrm{F}}\right) / n_{\mathrm{F}, 0} \times 100 \\
\text { Selectivity to GBL }(\%)=n_{\mathrm{G}} /\left(n_{\mathrm{F}, 0}-n_{\mathrm{F}}\right) \times 100
\end{gathered}
$$

where $n_{\mathrm{F}, 0}$ is the initial mole of $2(5 \mathrm{H})$-furanone loaded into the reactor, and $n_{\mathrm{G}}$ and $n_{\mathrm{F}}$ are the moles of GBL and 2(5H)-furanone, respectively.

To estimate the apparent reaction rate constant $\left(k_{\mathrm{r}}\right)$, the $2(5 \mathrm{H})$-furanone concentration $\left(C_{\mathrm{F}}\right)$ was fitted as a function of the reaction time based on Equation (4) with the reaction order $(p)$ fixed at 1.0. With the application of first-order law, the experimental data could be well described, with $\mathrm{R}^{2}>0.98$, for all five catalysts.

$$
\mathrm{d} C_{\mathrm{F}} / \mathrm{d} t=k_{\mathrm{r}} C_{\mathrm{F}}^{p}
$$

The initial turnover frequency (TOF) for the hydrogenation of $2(5 \mathrm{H})$-furanone to GBL was calculated as:

$$
\mathrm{TOF}_{\text {initial, } \mathrm{GBL}}=\left(k_{r} \times n_{\mathrm{F}, 0}\right) / n_{\text {active sites }} \times S_{\text {initial, } \mathrm{GBL}} s^{-1}
$$

where $S_{\text {initial,GBL }}$ is the initial selectivity to GBL obtained with the conversion of $2(5 \mathrm{H})$-furanone below $5 \%$. The mole of metal active sites ( $n_{\text {active sites }}$ ) was estimated by the CO chemisorption.

\section{Results}

\subsection{DFT calculations}

DFT calculations were carried out to compare the adsorptions of 2(5H)-furanone and GBL on both the monometallic and bimetallic surfaces with a Ni or Co layer placed either in the surface or subsurface. The top and side views of the DFT optimized configurations of $2(5 \mathrm{H})$-furanone and GBL on the Pt(111) surface are displayed in Figure 1, showing that 2(5H)-furanone binds to the $\mathrm{Pt}(111)$ surface through $\mathrm{C}$ atoms that have only one $\mathrm{C}-\mathrm{H}$ bond (Figure 1(b)), and that GBL 
primarily binds through the $\mathrm{O}$ atom in the $\mathrm{C}=\mathrm{O}$ bond (Figure $\mathbf{1}(\mathbf{c}))$. The d-band centers of $\mathrm{Pt}(111)$, Ni(111), Co(0001), Pt-Ni-Pt(111), Ni-Pt-Pt(111), Pt-Co-Pt(111) and Co-Pt-Pt(111) surfaces and the binding energies of atomic $\mathrm{H}, 2(5 \mathrm{H})$-furanone and $\mathrm{GBL}$ on these seven surfaces are summarized in Table 2. It should be noted that when the subsurface layer of $\operatorname{Pt}(111)$ is replaced by either $\mathrm{Ni}$ or $\mathrm{Co}$, the d-band of $\mathrm{Pt}$ is broadened and consequently the d-band center shifts away from the Fermi level. In contrast, the Ni-terminated and Co-terminated surfaces exhibit a d-band center closer to the Fermi level than $\mathrm{Ni}(111)$ and $\mathrm{Co}(0001)$, respectively. The binding energy of 2(5H)-furanone is less than $-0.20 \mathrm{eV}$ on Pt-Ni-Pt(111) and Pt-Co-Pt(111), while it increases to -1.65 and $-1.71 \mathrm{eV}$ on Ni-Pt-Pt(111) and Co-Pt-Pt(111), respectively. The binding energy of GBL on the three monometallic surfaces and two Pt-terminated bimetallic surfaces is similarly in the range of $-0.20 \sim-0.40 \mathrm{eV}$, whereas it significantly increases to -1.08 and $-1.22 \mathrm{eV}$ on Ni-Pt-Pt(111) and Co-Pt-Pt(111), respectively.

The DFT calculated binding energies of atomic $\mathrm{H}, 2(5 \mathrm{H})$-furanone and GBL on different model surfaces are plotted against the corresponding surface d-band center in Figure 2. It appears that the binding energies of atomic $\mathrm{H}, 2(5 \mathrm{H})$-furanone and $\mathrm{GBL}$ generally decrease as the surface d-band center shifts away from the Fermi level, which is consistent with the d-band model proposed by Nørskov and Hammer [41,42].

\subsection{TPD results}

TPD experiments of $2(5 \mathrm{H})$-furanone hydrogenation were performed on the hydrogen pre-dosed $\mathrm{Pt}(111), \mathrm{Ni} / \mathrm{Pt}(111), \mathrm{Co} / \mathrm{Pt}(111)$, thick Ni and thick Co surfaces. The TPD spectra of the desorbing gas phase species, 2(5H)-furanone $(\mathrm{m} / \mathrm{e}=55)$ and GBL $(\mathrm{m} / \mathrm{e}=86)$, are shown in Figure 3. As shown in Figure 3(a), a desorption peak of 2(5H)-furanone is observed at $200 \mathrm{~K}$ for all the 
surfaces, which is assigned to the physisorbed 2(5H)-furanone. For the Pt-Ni-Pt(111) and Pt-Co-Pt(111) surfaces, the detection of another desorption peak from the chemisorbed $2(5 \mathrm{H})$-furanone at $257 \mathrm{~K}$ suggests that less amount of $2(5 \mathrm{H})$-furanone is involved in the subsequent reaction on these two surfaces. Figure 3(b) compares the spectra of GBL on various surfaces. It shows that a large amount of GBL desorbs from the Ni-Pt-Pt(111) surface at $282 \mathrm{~K}$, and Co-Pt-Pt(111) surface also exhibits activity for the production of GBL. However, almost no GBL is detected from the Pt-Ni-Pt(111) and Pt-Co-Pt(111) surfaces, because 2(5H)-furanone might desorb from the surface before its hydrogenation. For monometallic surfaces, the thick $\mathrm{Ni}$ surface is found to be active for $2(5 \mathrm{H})$-furanone hydrogenation to GBL, while the thick Co and $\operatorname{Pt}(111)$ surfaces show no activity for the production of GBL.

The yield of GBL from the TPD measurements was determined by the following equation:

$$
\text { Yield of } \mathrm{C}_{4} \mathrm{H}_{6} \mathrm{O}_{2}=\left(\theta_{\mathrm{CO}}^{\text {sat }} / P_{\mathrm{CO}}^{\text {sat }}\right) \times P_{\mathrm{C}_{4} \mathrm{H}_{6} \mathrm{O}_{2}}^{\mathrm{C}_{\mathrm{H}_{2} \mathrm{O}_{2}}} \times\left(S_{28 \text { amu }}^{\mathrm{CO}} / S_{86}^{\mathrm{C}_{4} \mathrm{H}_{6} \mathrm{O}_{2}}\right)
$$

The $S_{86 \mathrm{amu}}^{\mathrm{C}_{4} \mathrm{H}_{6} \mathrm{O}_{2}}$ and $S_{28 \mathrm{amu}}^{\mathrm{CO}}$ are mass spectrometer sensitivities for GBL (86 amu) and CO (28 amu), respectively. The $P_{\mathrm{C}_{4} \mathrm{H}_{6} \mathrm{O}_{2}}^{\mathrm{C}_{4} \mathrm{O}_{2}}$ is the peak area of GBL from $2(5 \mathrm{H})$-furanone hydrogenation. The $P_{\mathrm{CO}}^{\text {sat }}$ is the peak area of $\mathrm{CO}$ from the saturated $\mathrm{CO}$ adsorption on $\mathrm{Pt}(111)$ and $\theta_{\mathrm{CO}}^{\text {sat }}$ is the saturation coverage of $\mathrm{CO}(0.68 \mathrm{ML})$ on $\mathrm{Pt}(111)$ [43]. The yield of GBL was determined by comparing the mass spectrometer sensitivity factors of GBL and $\mathrm{CO}$ at equal background concentrations of GBL and $\mathrm{CO}$. The yield of $\mathrm{CO}$ was obtained by comparing its TPD peak area with that after saturation exposure of $\mathrm{CO}$ on the $\mathrm{Pt}(111)$ surface. Table 3 summarizes the calculated yields of GBL from all the surfaces. The Ni (or Co)-Pt-Pt(111) surface exhibits a higher yield of GBL than that from either Pt(111) or thick Ni (or Co) surface, suggesting that the bimetallic formation enhances the hydrogenation of $2(5 \mathrm{H})$-furanone to GBL. Additionally, only a 
small amount of GBL is produced from the Pt-Ni-Pt(111) and Pt-Co-Pt(111) surfaces, as the majority of the chemisorbed $2(5 \mathrm{H})$-furanone desorbs at $257 \mathrm{~K}$ from these two surfaces. Other undesired decomposition products such as $\mathrm{CO}$ and propane were also observed in the TPD experiments, which were not discussed in this paper due to the different reaction environments between the UHV and autoclave experiments.

\subsection{Characterization of supported catalysts}

The CO chemisorption was employed to estimate the number of metal active sites for the $\mathrm{SiO}_{2}$-supported catalysts. The results are summarized in Table 1. The CO uptake values are 3.9, 3.6 and $3.1 \mu \mathrm{mol} \cdot \mathrm{g}^{-1}$ for $\mathrm{Pt} / \mathrm{SiO}_{2}, \mathrm{Ni} / \mathrm{SiO}_{2}$ and $\mathrm{Co} / \mathrm{SiO}_{2}$, respectively. The introduction of $\mathrm{Ni}$ into $\mathrm{Pt}$ increases the $\mathrm{CO}$ uptake value to $4.8 \mu \mathrm{mol} \cdot \mathrm{g}^{-1}$. However, the addition of Co to $\mathrm{Pt}$ does not significantly increase the CO binding sites and a CO uptake value of $4.0 \mu \mathrm{mol} \cdot \mathrm{g}^{-1}$ is obtained.

The TEM images and metal particle size distributions are shown in Figure 4, and the average metal particle sizes are listed in Table 1. For the $\mathrm{Pt} / \mathrm{SiO}_{2}$ monometallic catalyst, the metal particles mainly span the range of 1-6 nm with an average particle size of $2.7 \mathrm{~nm}$. After the addition of $\mathrm{Ni}$ and Co, the metal particle sizes are still distributed in a similar range, but the average metal particle sizes slightly increase to 3.4 and $4.0 \mathrm{~nm}$, respectively. In comparison, the other two monometallic catalysts, $\mathrm{Ni} / \mathrm{SiO}_{2}$ and $\mathrm{Co} / \mathrm{SiO}_{2}$, have much broader metal particle size distributions and larger average metal particle sizes.

Figure 5 shows the $\mathrm{H}_{2}$-TPR profiles of $\mathrm{SiO}_{2}$-supported catalysts. Two reduction peaks at 449 $\mathrm{K}$ and $692 \mathrm{~K}$ are observed for $\mathrm{Pt} / \mathrm{SiO}_{2}$. The appearance of two $\mathrm{H}_{2}$ consumption peaks for Pt was reported by Augustine for $\mathrm{Pt} / \mathrm{Al}_{2} \mathrm{O}_{3}$ [44], suggesting that they were caused by the reduction of two-dimensional $\mathrm{PtO}_{2}$ and three-dimensional platinum oxide. The $\mathrm{Ni} / \mathrm{SiO}_{2}$ exhibits a main 
reduction peak of $\mathrm{NiO}$ at $746 \mathrm{~K}$. The $\mathrm{Pt}-\mathrm{Ni} / \mathrm{SiO}_{2}$ bimetallic catalyst is reduced at a much lower temperature than $\mathrm{Ni} / \mathrm{SiO}_{2}$, as it exhibits a narrow and intense reduction peak at $560 \mathrm{~K}$. For $\mathrm{Co} / \mathrm{SiO}_{2}$, the first reduction peak at $630 \mathrm{~K}$ is assigned to the reduction of $\mathrm{Co}_{3} \mathrm{O}_{4}$ to $\mathrm{CoO}$ and the prolonged shoulder peak in the range of $725-867 \mathrm{~K}$ is caused by the subsequent reduction of $\mathrm{CoO}$ to metallic $\mathrm{Co}$ [45]. For the $\mathrm{Pt}-\mathrm{Co} / \mathrm{SiO}_{2}$ bimetallic catalyst, the two reduction peaks decrease to $483 \mathrm{~K}$ and $554 \mathrm{~K}$, respectively. Although the reduction temperatures of $\mathrm{Pt}-\mathrm{Ni} / \mathrm{SiO}_{2}$ and $\mathrm{Pt}-\mathrm{Co} / \mathrm{SiO}_{2}$ are higher than that of $\mathrm{Pt} / \mathrm{SiO}_{2}$, these three Pt-based catalysts can be completely reduced below $723 \mathrm{~K}$, at which temperature the catalysts were reduced before their catalytic evaluations.

\subsection{Catalytic evaluation of supported catalysts}

The $\mathrm{SiO}_{2}$-supported catalysts were evaluated in the liquid-phase hydrogenation of $2(5 \mathrm{H})$-furanone under the same reaction conditions. As shown in Figure 6(a), the selectivity to GBL over each tested catalyst is plotted as a function of $2(5 \mathrm{H})$-furanone conversion. The results show that for all five $\mathrm{SiO}_{2}$-supported catalysts, the selectivity to GBL gradually decreases with increasing conversion of $2(5 \mathrm{H})$-furanone. For example, with the conversion below $5 \%$, the selectivity to GBL over $\mathrm{Pt} / \mathrm{SiO}_{2}$ is approximately $80 \%$, while it decreases to $65.5 \%$ at a $2(5 \mathrm{H})$-furanone conversion of $100 \%$. For the monometallic catalysts, $\mathrm{Ni} / \mathrm{SiO}_{2}$ is more selective for the production of GBL than $\mathrm{Pt} / \mathrm{SiO}_{2}$ and $\mathrm{Co} / \mathrm{SiO}_{2}$. The $\mathrm{Pt}-\mathrm{Ni} / \mathrm{SiO}_{2}$ bimetallic catalyst shows a higher selectivity to GBL than both $\mathrm{Pt} / \mathrm{SiO}_{2}$ and $\mathrm{Ni} / \mathrm{SiO}_{2}$, indicating that the addition of $\mathrm{Ni}$ to $\mathrm{Pt}$ promotes the hydrogenation of the $\mathrm{C}=\mathrm{C}$ bond. Similarly, the $\mathrm{Pt}-\mathrm{Co} / \mathrm{SiO}_{2}$ bimetallic catalyst is also more selective to GBL than $\mathrm{Pt} / \mathrm{SiO}_{2}$ and $\mathrm{Co} / \mathrm{SiO}_{2}$. As summarized in Table 4, the final selectivity to $\mathrm{GBL}$ is $77.5 \%$ over $\mathrm{Pt}-\mathrm{Ni} / \mathrm{SiO}_{2}$ and $71.3 \%$ over $\mathrm{Pt}-\mathrm{Co} / \mathrm{SiO}_{2}$. In addition to GBL, side products including 2-hydroxytetrahydrofuran due to the hydrogenation of the $\mathrm{C}=\mathrm{O}$ bond, and methyl 
butyrate and butanediol due to the ring opening reactions were also detected with trace amounts in the reaction. The poor carbon balance of the products $(<80 \%)$ was most likely caused by the self-polymerization of $2(5 \mathrm{H})$-furanone, and the polymerizations between $2(5 \mathrm{H})$-furanone and other products existing in the reaction system.

To make a quantitative comparison for catalyst activity, the reaction rate constants are quantified by fitting a first-order rate law to the consumption of $2(5 \mathrm{H})$-furanone, as presented in Table 4. The reaction rate constants over $\mathrm{Pt} / \mathrm{SiO}_{2}\left(0.006 \mathrm{~min}^{-1}\right)$ and $\mathrm{Ni} / \mathrm{SiO}_{2}\left(0.005 \mathrm{~min}^{-1}\right)$ are similar, while $\mathrm{Co} / \mathrm{SiO}_{2}$ is less active with a reaction rate constant of $0.002 \mathrm{~min}^{-1}$. The addition of $\mathrm{Ni}$ and Co to Pt increases the reaction rate constant to $0.021 \mathrm{~min}^{-1}$ and $0.012 \mathrm{~min}^{-1}$, respectively, significantly higher than that over the corresponding monometallic catalysts. To further discuss the catalyst activity for the production of GBL, the initial TOFs for the hydrogenation of 2(5H)-furanone to GBL over the $\mathrm{SiO}_{2}$-supported catalysts are calculated and listed in Table 4. The TOF values over $\mathrm{Pt} / \mathrm{SiO}_{2}, \mathrm{Ni} / \mathrm{SiO}_{2}$ and $\mathrm{Co} / \mathrm{SiO}_{2}$ are $10.5,9.7$ and $4.5 \mathrm{~s}^{-1}$, respectively. Note that because the initial selectivity to GBL is used in Equation (5), the absolute TOF values are not identical to those in our previous work [11], but the trend of TOF among the three $\mathrm{SiO}_{2}$-supported monometallic catalysts is the same. For the $\mathrm{Pt}-\mathrm{Ni} / \mathrm{SiO}_{2}$ and $\mathrm{Pt}-\mathrm{Co} / \mathrm{SiO}_{2}$ bimetallic catalysts, the TOF for the hydrogenation of $2(5 \mathrm{H})$-furanone to GBL is determined to be 30.9 and $18.5 \mathrm{~s}^{-1}$, respectively. As the number of metal active sites was estimated by the $\mathrm{CO}$ chemisorption with the assumption that each absorbed $\mathrm{CO}$ molecule corresponded to one metal active site, the resulting TOFs were the average values.

In our previous work, the TOF for $2(5 \mathrm{H})$-furanone hydrogenation over a series of monometallic catalysts showed a volcano-type dependence on the d-band center, with Pd having 
the highest activity. Based on this volcano-type relationship between TOF and d-band center, the Pt-Ni (or Co) bimetallic catalyst should be less active than Pt and Ni (or Co). However, this is obviously inconsistent with the current observation as the two bimetallic catalysts do exhibit significantly enhanced activities, indicating that the d-band center alone is not a sufficient descriptor for the catalyst activity for bimetallic catalysts. Therefore it is necessary to further discuss the bimetallic effect based on the TPD and DFT results. In general, the catalyst activity follows the trend of $\mathrm{Pt}-\mathrm{Ni} / \mathrm{SiO}_{2}>\mathrm{Pt}-\mathrm{Co} / \mathrm{SiO}_{2}>\mathrm{Pt} / \mathrm{SiO}_{2}>\mathrm{Ni} / \mathrm{SiO}_{2}>\mathrm{Co} / \mathrm{SiO}_{2}$, while the final selectivity to GBL shows the trend of $\mathrm{Pt}-\mathrm{Ni} / \mathrm{SiO}_{2}>\mathrm{Ni} / \mathrm{SiO}_{2}>\mathrm{Pt}-\mathrm{Co} / \mathrm{SiO}_{2}>\mathrm{Co} / \mathrm{SiO}_{2}>\mathrm{Pt} / \mathrm{SiO}_{2}$, as illustrated in Figure 6(b).

\section{Discussion}

The results above demonstrate that Pt-Ni and Pt-Co bimetallic catalysts are more active for the selective hydrogenation of $2(5 \mathrm{H})$-furanone to GBL than the corresponding monometallic catalysts. The enhanced hydrogenation activities of the bimetallic catalysts are further discussed in this section by several correlations between the model surfaces and supported catalysts. In the TPD experiments, both the Ni-Pt-Pt(111) and Co-Pt-Pt(111) bimetallic surfaces with $\mathrm{Ni}$ or Co on the top layer exhibit a higher yield of GBL than the corresponding monometallic surfaces. According to the DFT calculations, the binding energy of $2(5 \mathrm{H})$-furanone is significantly higher on Ni-Pt-Pt(111) and Co-Pt-Pt(111) than that on the other surfaces. In addition, the binding energy

of GBL is lower than that of $2(5 \mathrm{H})$-furanone on the same surface. In contrast, both the Pt-terminated bimetallic surfaces, $\mathrm{Pt}-\mathrm{Ni}-\mathrm{Pt}(111)$ and $\mathrm{Pt}-\mathrm{Co}-\mathrm{Pt}(111)$, are found to be almost inactive for the production of GBL in the TPD experiments. This is consistent with the DFT calculations, which shows that the binding of $2(5 \mathrm{H})$-furanone on the two subsurface structures is too weak, 
leading to desorption of $2(5 \mathrm{H})$-furanone from the surface before hydrogenation reaction. However, correlating the GBL yield from 2(5H)-furanone hydrogenation in the TPD experiments with respect to the DFT calculated binding energy of $2(5 \mathrm{H})$-furanone on all seven model surfaces results in a poor correlation, as shown in Figure 7(a). This result suggests that neither the binding energy of $2(5 \mathrm{H})$-furanone nor the surface d-band center alone is a sufficient descriptor for the hydrogenation activity when both monometallic and bimetallic surfaces are included in the current study.

Further DFT calculations were performed to estimate the activation energy $\left(E_{\mathrm{a}}\right)$ and reaction energy $(\Delta E)$ of elementary steps in the selective hydrogenation of $2(5 \mathrm{H})$-furanone to GBL on the most active surface, Ni-Pt-Pt(111), and the unmodified $\mathrm{Pt}(111)$ as a reference. The results are displayed in Table 5, which shows that the hydrogenation of $2(5 \mathrm{H})$-furanone to the $\mathrm{C}_{4} \mathrm{H}_{5} \mathrm{O}_{2}$ intermediate on $\operatorname{Pt}(111)$ has $E_{\mathrm{a}}=0.65 \mathrm{eV}$ and $\Delta E=-0.13 \mathrm{eV}$. Further hydrogenation of $\mathrm{C}_{4} \mathrm{H}_{5} \mathrm{O}_{2}$ to GBL on $\mathrm{Pt}(111)$ has $E_{\mathrm{a}}=1.00 \mathrm{eV}$ and $\Delta E=0.01 \mathrm{eV}$. It is noted that the desorption energy of $2(5 \mathrm{H})$-furanone $(0.73 \mathrm{eV})$ (Table 2) is comparable to the $E_{\mathrm{a}}(0.65 \mathrm{eV})$ of its hydrogenation to $\mathrm{C}_{4} \mathrm{H}_{5} \mathrm{O}_{2}$. Thus $2(5 \mathrm{H})$-furanone desorption is kinetically competing with $2(5 \mathrm{H})$-furanone hydrogenation. However, entropy contribution at experimental reaction conditions significantly favors the desorption of $2(5 \mathrm{H})$-furanone over its hydrogenation. On Ni-Pt-Pt(111), the hydrogenation of $2(5 \mathrm{H})$-furanone to $\mathrm{C}_{4} \mathrm{H}_{5} \mathrm{O}_{2}$ and $\mathrm{C}_{4} \mathrm{H}_{5} \mathrm{O}_{2}$ to $\mathrm{GBL}$ has $E_{\mathrm{a}}=0.80 \mathrm{eV}, \Delta E=0.26 \mathrm{eV}$ and $E_{\mathrm{a}}=0.58 \mathrm{eV}, \Delta E=0.17 \mathrm{eV}$, respectively. The $E_{\mathrm{a}}(0.80 \mathrm{eV})$ of $2(5 \mathrm{H})$-furanone hydrogenation to $\mathrm{C}_{4} \mathrm{H}_{5} \mathrm{O}_{2}$ on Ni-Pt-Pt(111) is significantly lower than its desorption energy $(1.65 \mathrm{eV})$. As a result, $2(5 \mathrm{H})$-furanone hydrogenation is kinetically competing with $2(5 \mathrm{H})$-furanone desorption even after including the entropy contribution. Furthermore, it is found that the $E_{\mathrm{a}}$ of the rate-determining 
hydrogenation step $\left({ }^{*} \mathrm{C}_{4} \mathrm{H}_{5} \mathrm{O}_{2}+{ }^{*} \mathrm{H} \rightarrow{ }^{*} \mathrm{C}_{4} \mathrm{H}_{6} \mathrm{O}_{2}\right.$ on $\mathrm{Pt}(111)$ and ${ }^{*} \mathrm{C}_{4} \mathrm{H}_{4} \mathrm{O}_{2}+* \mathrm{H} \rightarrow{ }^{*} \mathrm{C}_{4} \mathrm{H}_{5} \mathrm{O}_{2}$ on Ni-Pt-Pt(111)) is lower on Ni-Pt-Pt(111) than on $\mathrm{Pt}(111)$. Thus the DFT results predict a higher activity of Ni-Pt-Pt(111) compared to $\mathrm{Pt}(111)$ for the selective hydrogenation of $2(5 \mathrm{H})$-furanone to GBL, in agreement with the corresponding TPD measurements.

The DFT and TPD predictions on model surfaces are validated by the catalytic evaluation of $\mathrm{SiO}_{2}$-supported catalysts, where the initial TOFs of $\mathrm{Pt}-\mathrm{Ni} / \mathrm{SiO}_{2}$ and $\mathrm{Pt}-\mathrm{Co} / \mathrm{SiO}_{2}$ are higher than that of $\mathrm{Pt} / \mathrm{SiO}_{2}$. Figure 7(b) displays the correlation of the initial $\mathrm{TOF}$ for $2(5 \mathrm{H})$-furanone hydrogenation to GBL over $\mathrm{SiO}_{2}$-supported Pt, Pt-Ni and Pt-Co catalysts with the hydrogenation activity of 2(5H)-furanone to GBL on Pt(111), Ni-Pt-Pt(111) and Co-Pt-Pt(111) model surfaces from TPD experiments. The nearly linear relationship demonstrates an excellent correlation between the model surfaces and supported catalysts. It should be noted that the $\mathrm{Pt} / \mathrm{SiO}_{2}$ monometallic catalyst does show activity for hydrogenation of $2(5 \mathrm{H})$-furanone to $\mathrm{GBL}$ in the catalytic evaluations, whereas no GBL is detected from the $\operatorname{Pt}(111)$ surface in TPD experiments. This inconsistency between the $\mathrm{Pt}(111)$ model surface and the supported $\mathrm{Pt} / \mathrm{SiO}_{2}$ catalyst is probably due to the differences between the UHV-TPD experimental conditions and the high-pressure reactor evaluation conditions.

The correlation between the model surfaces and supported catalysts suggests that the enhanced hydrogenation activity of the supported Pt-Ni bimetallic catalyst is likely due to the presence of a Ni-terminated surface structure. Previous DFT calculations and UHV experiments over model $\mathrm{Ni} / \mathrm{Pt}(111)$ surfaces $[46,47]$ indicated that the surface termination could change depending on the nature of the adsorbates. In addition, in a previous study using in-situ EXAFS [48] over supported Pt-Ni bimetallic catalysts for the reaction with ethylene glycol, the catalysts 
changed from a Pt-terminated surface after $\mathrm{H}_{2}$ reduction to mainly Ni-terminated surface after the introduction of ethylene glycol. In the current study, the hydrogenation reaction was carried out using methanol as the solvent, and both the reactants and products contained oxygen atoms, suggesting the possibility of the presence of Ni-terminated bimetallic structure. In-situ EXAFS studies are needed to determine the surface termination of the bimetallic catalysts under reaction conditions.

\section{Conclusions}

The selective hydrogenation of biomass-derived $2(5 \mathrm{H})$-furanone has been investigated by the combined DFT, surface science and reactor studies. Based on the results and discussion presented above, the following conclusions could be made: (1) TPD results show that the Ni (or Co)-Pt-Pt(111) bimetallic surface is more active than its monometallic counterparts; (2) DFT calculations confirm the higher hydrogenation activity on Ni-Pt-Pt(111), as the $E_{\text {a }}$ of the hydrogenation step is lower on Ni-Pt-Pt(111) than on Pt(111); (3) The reactor studies show that the Pt-Ni/SiO ${ }_{2}$ and $\mathrm{Pt}-\mathrm{Co} / \mathrm{SiO}_{2}$ bimetallic catalysts are much more active than the corresponding monometallic catalysts, and the introduction of $\mathrm{Ni}$ and $\mathrm{Co}$ into Pt also improves the selectivity to

GBL; (4) The good correlation between model surfaces and supported catalysts demonstrates the feasibility of employing this combined approach to guide the design of bimetallic catalysts for 2(5H)-furanone hydrogenation.

\section{Acknowledgement}

This work was supported by the National Natural Science Foundation of China (No. 21476122) and Program for New Century Excellent Talents in University of China (NCET-12-0297). Contributions from Columbia University (for DFT and UHV studies) were 
funded through the Catalysis Center for Energy Innovation (CCEI), an Energy Frontier Research Center funded by the U.S. Department of Energy, Office of Science, Office of Basic Energy Sciences under Award No. DE-SC0001004.

\section{References}

[1] R.A. Sheldon, Green Chem. 16 (2014) 950.

[2] D.M. Alonso, S.G. Wettstein, J.A. Dumesic, Chem. Soc. Rev. 41 (2012) 8075.

[3] S. Shi, H. Guo, G. Yin, Catal Commun. 12 (2011) 731.

[4] H. Choudhary, S. Nishimura, K. Ebitani, Appl. Catal. A: Gen. 458 (2013) 55.

[5] L.A. Badovskaya, V.M. Latashko, V.V. Poskonin, E.P. Grunskaya, Z.I. Tyukhteneva, S.G. Rudakova, S.A. Pestunova, A.V. Sarkisyan, J. Heterocycl. Chem. 38 (2002) 1040.

[6] J.P. Lange, E. van der Heide, J. van Buijtenen, R. Price, ChemSusChem 5 (2012) 150.

[7] X. Li, X. Lan, T. Wang, Catal Today (2016), http://dx.doi.org/10.1016/j.cattod.2015.11.036

[8] A. Hashmen, E. Kleinpeter, Adv. Heterocycl. Chem. 81 (2001) 107.

[9] N. Ichikawa, S. Sato, R. Takahashi, T. Sodesawa, K. Inui, J. Mol. Catal. A: Chem. 21 (2004) 197.

[10] S. Fernando, S. Adhikari, C. Chandrapal, N. Murali, Energy Fuels 20 (2006) 1727.

[11] X. Li, X. Lan, T. Wang, Green Chem. 8 (2016) 638.

[12] S. Zafeiratos, S. Piccinin, D. Teschner, Catal. Sci. Technol. 2 (2012) 1787.

[13] W. Yu, M.D. Porosoff, J.G. Chen, Chem. Rev. 112 (2012) 5780.

[14] J.A. Rodriguez, Surf. Sci. Rep. 24 (1996) 223.

[15] S. Lu, W.W. Lonergan, J.P. Bosco, S. Wang, Y. Zhu, Y. Xie, J.G. Chen, J. Catal. 259 (2008) 260. 
[16] R. Zheng, M.D. Porosoff, J.L. Weiner, S. Lu, Y. Zhu, J.G. Chen, Appl. Catal. A: Gen. 419 (2012) 126.

[17] J. Li, P. Tian, X. Wang, L. Shi, Chem. Eng. J. 175 (2011) 417.

[18] U.R. Pillai, E. Sahle-Demessie, D. Young, Appl. Catal. B: Environ. 43 (2003) 131.

[19] Q. Wang, H.Y. Cheng, R.X. Liu, J.M. Hao, Y.C. Yu, S.X. Cai, F.Y. Zhao, Catal. Commun. 10 (2009) 592.

[20] S. Sitthisa, T. Sooknoi, Y. Ma, P.B. Balbuena, D.E. Resasco, J. Catal. 277 (2011) 1.

[21] K. Xiong, W. Yu, D.V. Vlachos, J.G. Chen, ChemCatChem 7 (2015) 1402.

[22] D.W. Goodman, Ultramicroscopy 34 (1990) 1.

[23] J. Lee, Y. Xu, G.W. Huber, Appl. Catal. B: Environ. 140 (2013) 98.

[24] V. Vorotnikov, G. Mpourmpakis, D.G. Vlachos, ACS Catal. 2 (2012) 2496.

[25] M.N.Z. Myint, Y. Yan, J.G. Chen, J. Phys. Chem. C 118 (2014) 11340.

[26] M.N.Z. Myint, J.G. Chen, ACS Catal. 5 (2015) 256.

[27] H. Zhao, B.E. Koel, J. Catal. 234 (2005) 24.

[28] S. Qi, W. Yu, W.W. Lonergan, B. Yan, J.G. Chen, ChemCatChem 2 (2012) 625.

[29] S. Lu, W.W. Lonergan, Y. Zhu, Y. Xie, J.G. Chen, Appl. Catal. B: Environ. 91 (2009) 610.

[30] C.M. Ammann, G.A. Meehl, W.M. Washington, C.S. Zender, Geophys. Res. Lett. 30 (2003) 1657.

[31] G. Kresse, J. Furthmuller, Phys. Rev. B 54 (1996) 11169.

[32] G. Kresse, J. Furthmuller, Comput. Mater. Sci. 6 (1996) 15.

[33] G. Kresse, J. Hafner, Phys. Rev. B 47 (1993) 558.

[34] J.P. Perdew, J.A. Chevary, S.H. Vosko, K.A. Jackson, M.R. Pederson, D.J. Singh, C. Fiolhais, 
Phys. Rev. B 46 (1992) 6671.

[35] M.P. Teter, M.C. Payne, D.C. Allan, Phys. Rev. B 40 (1989) 12255.

[36] G. Henkelman, B.P. Uberuaga, H. Jonsson, J. Chem. Phys. 113 (2000) 9901.

[37] A.Ruban, B. Hammer, P.Stoltze, H. L. Skriver, J. K. Nørskov, J. Mol. Catal. A: Chem. 115 (1997) 421.

[38] W. Yu, M.A. Barteau, J.G. Chen, J. Am. Chem. Soc. 133 (2011) 20528.

[39] N.A. Khan, H.H. Hwu, J.G. Chen, J. Catal. 205 (2002) 259.

[40] W.W. Lonergan, D.G. Vlachos, J.G. Chen, J. Catal. 271 (2010) 239.

[41] B. Hammer, J. K. Nørskov, Surf. Sci. 343 (1995) 211.

[42] B. Hammer, O. H. Nielsen, J. K. Nørskov, Catal. Lett. 46 (1997) 31.

[43] G. Ertl, M. Neumann, K. M. Streit, Surf. Sci. 64 (1977) 393.

[44] S.M. Augustine, W.M.H. Sachtler, J. Catal. 116 (1989) 184.

[45] M. Guo, G. Lu, React. Kinet. Mech. Cat. 113 (2014) 101.

[46] C.A. Menning, J.G. Chen, J. Chem. Phys. 130 (2009) 174709.

[47] C.A. Menning, H.H. Hwu, J.G. Chen, J. Phys. Chem. B 110 (2006) 15471.

[48] S.A. Tupy, A.M. Karim, C. Bagia, W. Deng, Y. Huang, D.G. Vlachos, J.G. Chen, ACS Catal. $2(2012) 2290$ 


\section{Table captions}

Table 1 Catalyst composition, average metal particle size and CO uptake.

Table 2 The d-band centers and binding energies of atomic H, 2(5H)-furanone $\left(\mathrm{C}_{4} \mathrm{H}_{4} \mathrm{O}_{2}\right)$ and $\operatorname{GBL}\left(\mathrm{C}_{4} \mathrm{H}_{6} \mathrm{O}_{2}\right)$ on model surfaces.

Table 3 Yield of GBL on metal surfaces from TPD measurements.

Table 4 Catalytic performances of $\mathrm{SiO}_{2}$-supported catalysts.

Table 5 Activation energies $\left(E_{\mathrm{a}}\right)$ and reaction energies $(\Delta E)$ of selective hydrogenation of 2(5H)-furanone $\left(\mathrm{C}_{4} \mathrm{H}_{4} \mathrm{O}_{2}\right)$ to $\mathrm{GBL}\left(\mathrm{C}_{4} \mathrm{H}_{6} \mathrm{O}_{2}\right)$ on $\mathrm{Pt}(111)$ and Ni-Pt-Pt(111) surfaces. 
Table 1 Catalyst composition, average metal particle size and CO uptake.

\begin{tabular}{llll}
\hline Entry & Catalyst $^{a}$ & $\begin{array}{l}\text { Average metal particle size } \\
(\mathrm{nm})\end{array}$ & $\begin{array}{l}\text { CO uptake } \\
\left(\mu \mathrm{mol} \cdot \mathrm{g}^{-1}\right)\end{array}$ \\
\hline 1 & $0.5 \% \mathrm{Pt} / \mathrm{SiO}_{2}$ & 2.7 & 3.9 \\
2 & $0.5 \% \mathrm{Ni} / \mathrm{SiO}_{2}$ & 4.6 & 3.6 \\
3 & $0.5 \% \mathrm{Pt}-0.5 \% \mathrm{Ni}^{\prime} / \mathrm{SiO}_{2}$ & 3.4 & 4.8 \\
4 & $0.5 \% \mathrm{Co} / \mathrm{SiO}_{2}$ & 4.3 & 3.1 \\
5 & $0.5 \% \mathrm{Pt}-0.5 \% \mathrm{Co} / \mathrm{SiO}_{2}$ & 4.0 & 4.0 \\
\hline
\end{tabular}

${ }^{a}$ The $\mathrm{SiO}_{2}$-supported catalysts were denoted as $x \% \mathrm{M}_{1}-y \% \mathrm{M}_{2} / \mathrm{SiO}_{2}$, where $x$ and $y$ were the loadings in wt $\%$ of the supported metals.

${ }^{b}$ The average metal particle size was determined by TEM. 
Table 2 The d-band centers and binding energies of atomic H, 2(5H)-furanone $\left(\mathrm{C}_{4} \mathrm{H}_{4} \mathrm{O}_{2}\right)$ and GBL $\left(\mathrm{C}_{4} \mathrm{H}_{6} \mathrm{O}_{2}\right)$ on model surfaces.

\begin{tabular}{llllll}
\hline \multirow{2}{*}{ Entry } & Surface & $\mathrm{d}$-band center $(\mathrm{eV})$ & \multicolumn{3}{l}{ Binding energy $(\mathrm{eV})$} \\
\cline { 4 - 6 } & & $\mathrm{H}$ & $\mathrm{C}_{4} \mathrm{H}_{4} \mathrm{O}_{2}$ & $\mathrm{C}_{4} \mathrm{H}_{6} \mathrm{O}_{2}$ \\
\hline 1 & $\mathrm{Pt}(111)$ & -2.57 & -2.75 & -0.73 & -0.28 \\
2 & $\mathrm{Ni}(111)$ & -1.45 & -2.83 & -0.49 & -0.24 \\
3 & $\mathrm{Co}(0001)$ & -1.35 & -2.78 & -0.36 & -0.30 \\
4 & $\mathrm{Pt}-\mathrm{Ni}-\mathrm{Pt}(111)$ & -2.75 & -2.54 & -0.19 & -0.21 \\
5 & $\mathrm{Ni-Pt-Pt(111)}$ & -1.20 & -3.02 & -1.65 & -1.08 \\
6 & $\mathrm{Pt}-\mathrm{Co}-\mathrm{Pt}(111)$ & -2.95 & -2.40 & -0.04 & -0.23 \\
7 & $\mathrm{Co}-\mathrm{Pt}-\mathrm{Pt}(111)$ & -1.00 & -3.01 & -1.71 & -1.22 \\
\hline
\end{tabular}


Table 3 Yield of GBL on metal surfaces from TPD measurements.

\begin{tabular}{lll}
\hline Entry & Surface $^{a}$ & Yield of GBL $\left(10^{-2}\right)$ \\
\hline 1 & $\operatorname{Pt}(111)$ & 0.0 \\
2 & $\mathrm{Ni}(111)$ & 6.8 \\
3 & $\mathrm{Co}(0001)$ & 0.0 \\
4 & $\operatorname{Pt}-\mathrm{Ni}-\mathrm{Pt}(111)$ & 1.0 \\
5 & $\mathrm{Ni}-\mathrm{Pt}-\mathrm{Pt}(111)$ & 11.6 \\
6 & Pt-Co-Pt(111) & 0.6 \\
7 & Co-Pt-Pt(111) & 2.3 \\
\hline
\end{tabular}

${ }^{a}$ The TPD experiments were carried out on hydrogen pre-dosed metal surfaces. 
Table 4 Catalytic performances of $\mathrm{SiO}_{2}$-supported catalysts.

\begin{tabular}{lllll}
\hline Entry & Catalyst $^{a}$ & $k_{\mathrm{r}}\left(10^{-2} \cdot \mathrm{min}^{-1}\right)^{b}$ & $\mathrm{TOF}\left(\mathrm{s}^{-1}\right)$ & Selectivity to GBL $(\%)^{c}$ \\
\hline 1 & $\mathrm{Pt} / \mathrm{SiO}_{2}$ & 0.6 & 10.5 & 65.5 \\
2 & $\mathrm{Ni} / \mathrm{SiO}_{2}$ & 0.5 & 9.7 & 71.6 \\
3 & $\mathrm{Pt}-\mathrm{Ni}_{\mathrm{SiO}}$ & 2.1 & 30.9 & 77.5 \\
4 & $\mathrm{Co} / \mathrm{SiO}_{2}$ & 0.2 & 4.5 & 67.9 \\
5 & $\mathrm{Pt}-\mathrm{Co} / \mathrm{SiO}_{2}$ & 1.2 & 18.5 & 71.3 \\
\hline
\end{tabular}

${ }^{a}$ Reaction conditions: $2(5 \mathrm{H})$-furanone $(6.0 \mathrm{~g})$, catalyst $(0.15 \mathrm{~g}), 100 \mathrm{~mL}$ of methanol as the solvent, $353 \mathrm{~K}, 3.5 \mathrm{MPa} \mathrm{H}_{2}, 180 \mathrm{~mL} \cdot \mathrm{min}^{-1} \mathrm{H}_{2}$ gas flow, $800 \mathrm{rpm}$ stirring.

${ }^{b}$ The reaction order was assumed to be 1.0 with respect to $2(5 \mathrm{H})$-furanone.

${ }^{c}$ The selectivity to GBL was calculated with $2(5 \mathrm{H})$-furanone just completely converted. 
Table 5 Activation energies $\left(E_{\mathrm{a}}\right)$ and reaction energies $(\Delta E)$ of selective hydrogenation of 2(5H)-furanone $\left(\mathrm{C}_{4} \mathrm{H}_{4} \mathrm{O}_{2}\right)$ to $\mathrm{GBL}\left(\mathrm{C}_{4} \mathrm{H}_{6} \mathrm{O}_{2}\right)$ on $\mathrm{Pt}(111)$ and Ni-Pt-Pt(111) surfaces.

\begin{tabular}{lllll}
\hline \multirow{2}{*}{ Reaction } & \\
& \multicolumn{2}{l}{$\mathrm{Pt}(111)$} & \multicolumn{3}{c}{ Ni-Pt-Pt(111) } \\
\cline { 2 - 5 } & $E_{\mathrm{a}}(\mathrm{eV})$ & $\Delta E(\mathrm{eV})$ & $E_{\mathrm{a}}(\mathrm{eV})$ & $\Delta E(\mathrm{eV})$ \\
\hline${ }^{*} \mathrm{C}_{4} \mathrm{H}_{4} \mathrm{O}_{2}+* \mathrm{H} \rightarrow * \mathrm{C}_{4} \mathrm{H}_{5} \mathrm{O}_{2}+*$ & 0.65 & -0.13 & 0.80 & 0.26 \\
$* \mathrm{C}_{4} \mathrm{H}_{5} \mathrm{O}_{2}+* \mathrm{H} \rightarrow * \mathrm{C}_{4} \mathrm{H}_{6} \mathrm{O}_{2}+*$ & 1.00 & 0.01 & 0.58 & 0.17 \\
\hline
\end{tabular}

${ }^{a}$ The surface species are denoted as*. 


\section{Figure captions}

Fig. 1 Top (bottom) and side (top) views of DFT optimized geometries of (a) Pt(111) surface, (b) 2(5H)-furanone on $\mathrm{Pt}(111)$ surface and (c) GBL on $\mathrm{Pt}(111)$ surface.

Fig. 2 Binding energies of atomic $\mathrm{H}, 2(5 \mathrm{H})$-furanone $\left(\mathrm{C}_{4} \mathrm{H}_{4} \mathrm{O}_{4}\right)$ and $\mathrm{GBL}\left(\mathrm{C}_{4} \mathrm{H}_{6} \mathrm{O}_{4}\right)$ vs surface d-band center for monometallic and bimetallic model surfaces.

Fig. 3 TPD spectra of (a) 2(5H)-furanone and (b) GBL following $4 \mathrm{~L}$ exposure of 2(5H)-furanone on metal surfaces.

Fig. 4 TEM images and metal particle size distributions of (a) $\mathrm{Pt} / \mathrm{SiO}_{2}$, (b) $\mathrm{Ni} / \mathrm{SiO}_{2}$, (c) $\mathrm{Pt}-\mathrm{Ni} / \mathrm{SiO}_{2}$, (d) $\mathrm{Co} / \mathrm{SiO}_{2}$ and (e) $\mathrm{Pt}-\mathrm{Co} / \mathrm{SiO}_{2}$.

Fig. $5 \mathrm{H}_{2}$-TPR profiles of the $\mathrm{SiO}_{2}$-supported catalysts.

Fig. 6 Catalytic performances of the $\mathrm{SiO}_{2}$-supported catalysts.

Fig. 7 Hydrogenation activity of 2(5H)-furanone to GBL from TPD experiments $v s$ (a) DFT calculated binding energy of $2(5 \mathrm{H})$-furanone on model surfaces and (b) TOF over the $\mathrm{SiO}_{2}$-supported catalysts. 
(a)
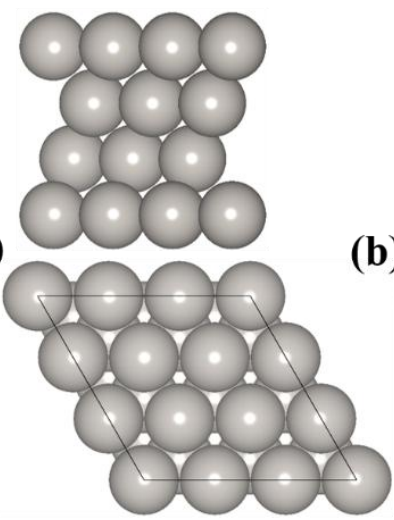

(b)
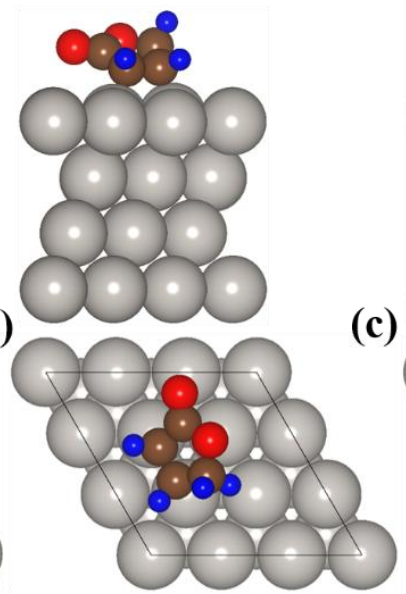

(c)
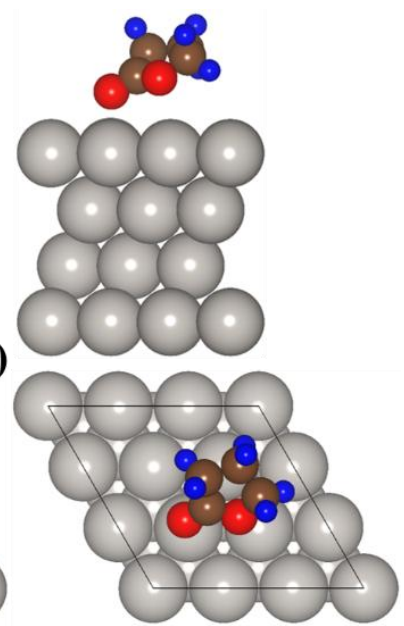

Fig. 1 Top (bottom) and side (top) views of DFT optimized geometries of (a) $\operatorname{Pt}(111)$ surface, (b) 2(5H)-furanone on $\mathrm{Pt}(111)$ surface and (c) GBL on $\mathrm{Pt}(111)$ surface. Pt: light grey, O: red, C: brown and H: blue. 


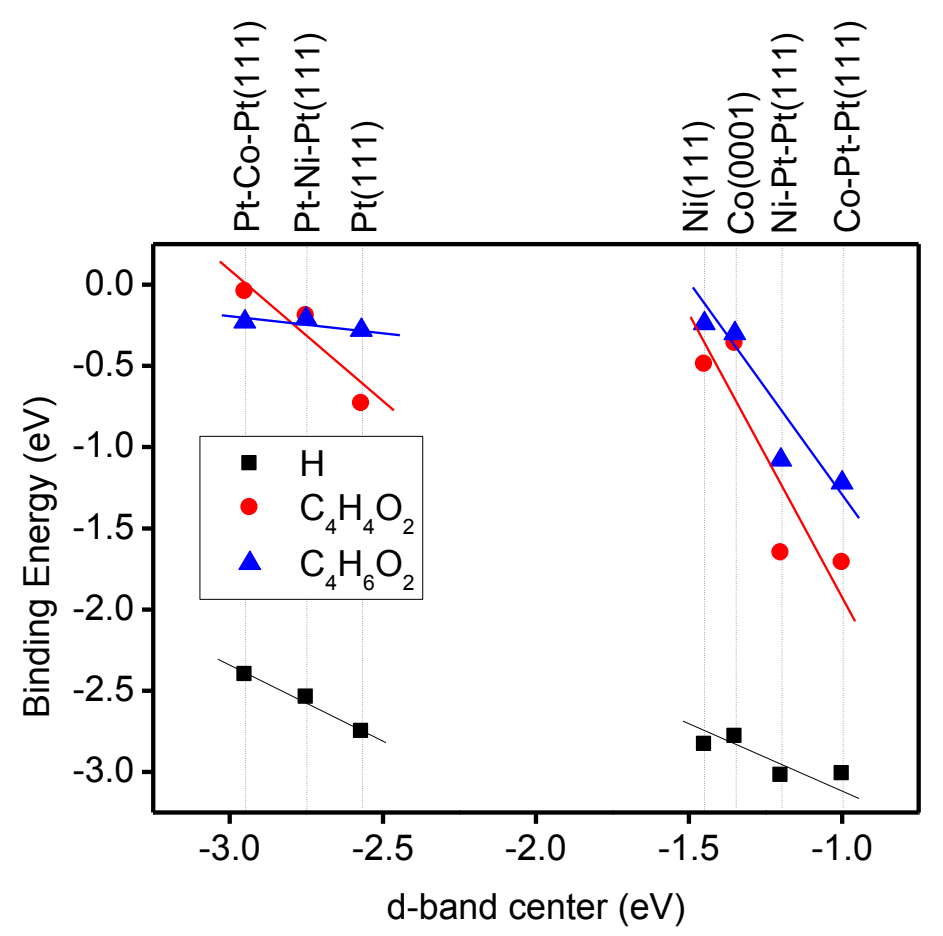

Fig. 2 Binding energies of atomic $\mathrm{H}, 2(5 \mathrm{H})$-furanone $\left(\mathrm{C}_{4} \mathrm{H}_{4} \mathrm{O}_{4}\right)$ and $\mathrm{GBL}\left(\mathrm{C}_{4} \mathrm{H}_{6} \mathrm{O}_{4}\right)$ vs surface d-band center for monometallic and bimetallic model surfaces. 

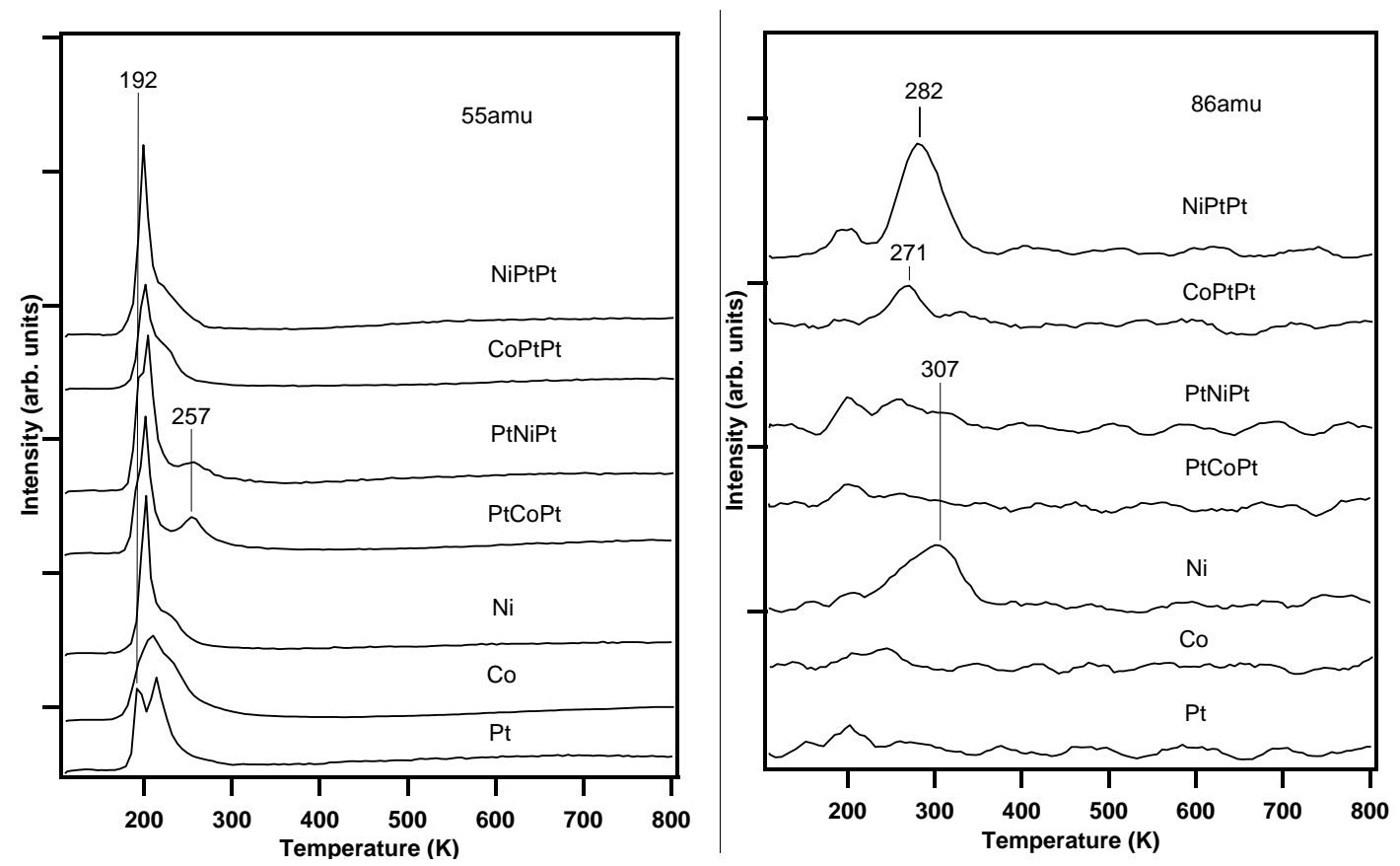

Fig. 3 TPD spectra of (a) 2(5H)-furanone and (b) GBL following $4 \mathrm{~L}$ exposure of 2(5H)-furanone on metal surfaces. 

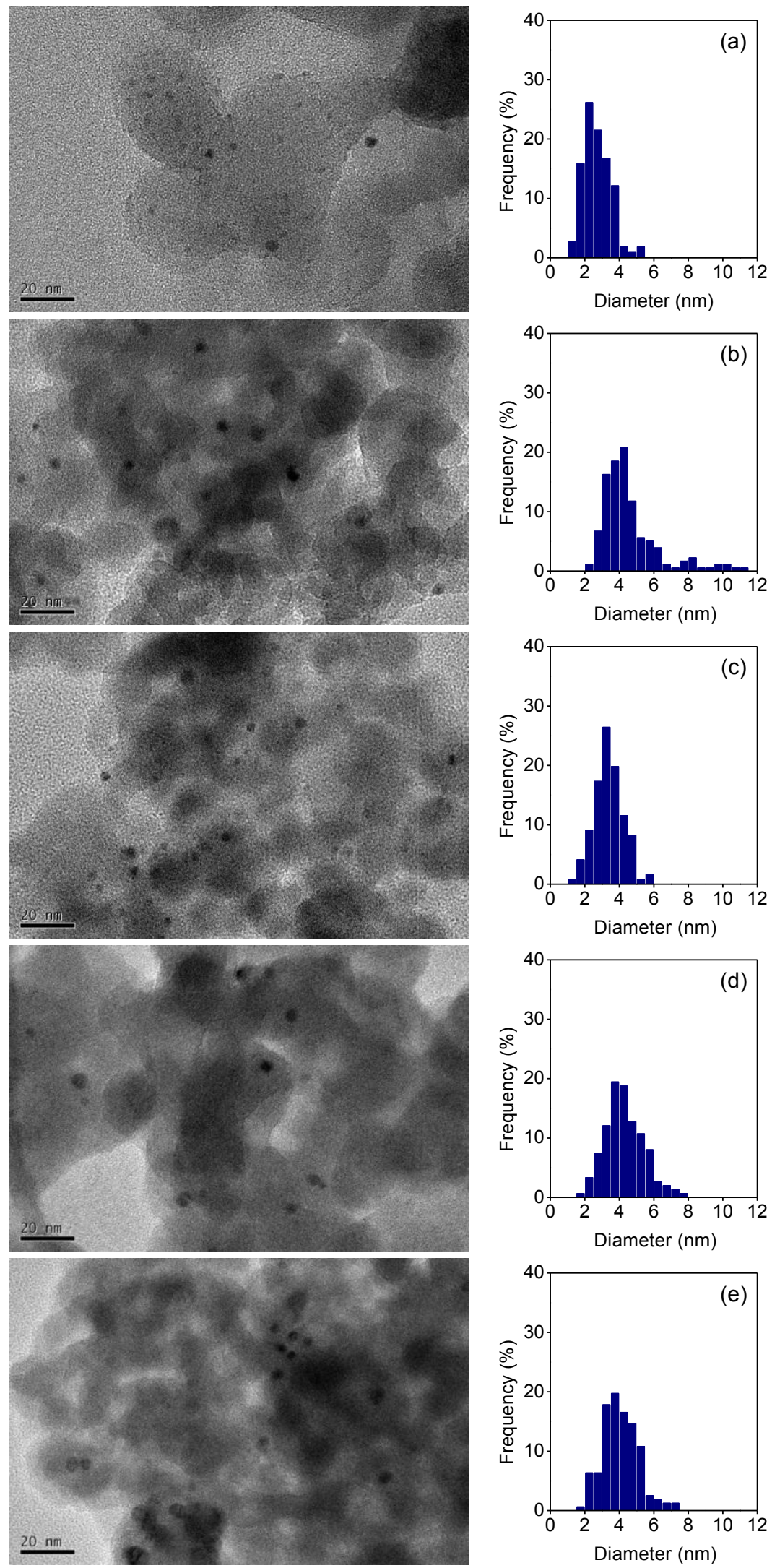

Fig. 4 TEM images and metal particle size distributions of (a) $\mathrm{Pt} / \mathrm{SiO}_{2}$, (b) $\mathrm{Ni} / \mathrm{SiO}_{2}$, (c) $\mathrm{Pt}-\mathrm{Ni} / \mathrm{SiO}_{2}$, (d) $\mathrm{Co} / \mathrm{SiO}_{2}$ and (e) $\mathrm{Pt}-\mathrm{Co} / \mathrm{SiO}_{2}$. 


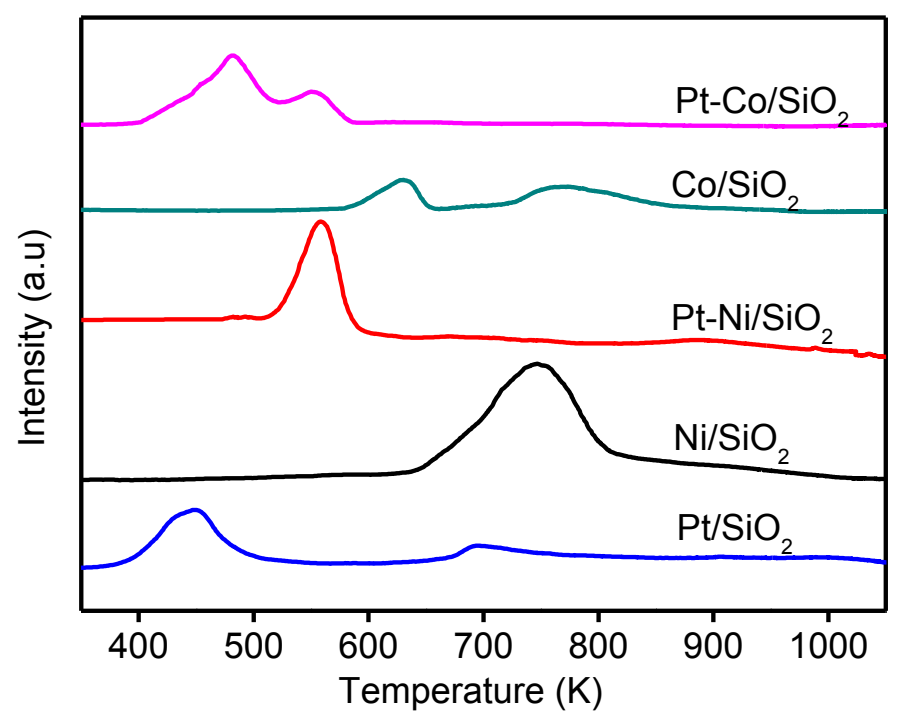

Fig. $5 \mathrm{H}_{2}$-TPR profiles of the $\mathrm{SiO}_{2}$-supported catalysts. 

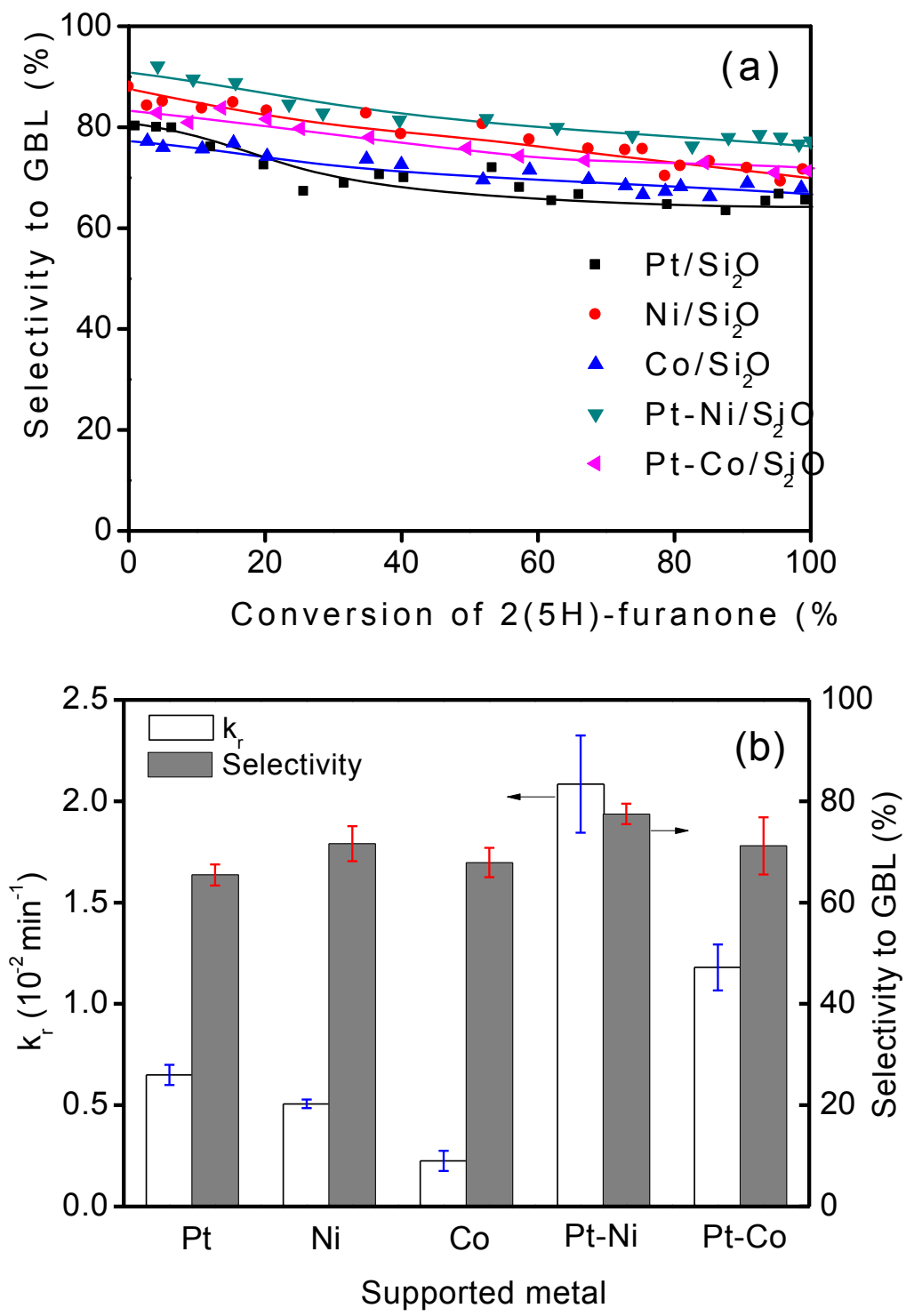

Fig. 6 Catalytic performances of the $\mathrm{SiO}_{2}$-supported catalysts.

Reaction conditions: $2(5 \mathrm{H})$-furanone $(6.0 \mathrm{~g})$, catalyst $(0.15 \mathrm{~g}), 100 \mathrm{~mL}$ of methanol as the solvent, $353 \mathrm{~K}, 3.5 \mathrm{MPa} \mathrm{H}_{2}, 180 \mathrm{~mL} \cdot \mathrm{min}^{-1} \mathrm{H}_{2}$ gas flow, $800 \mathrm{rpm}$. 

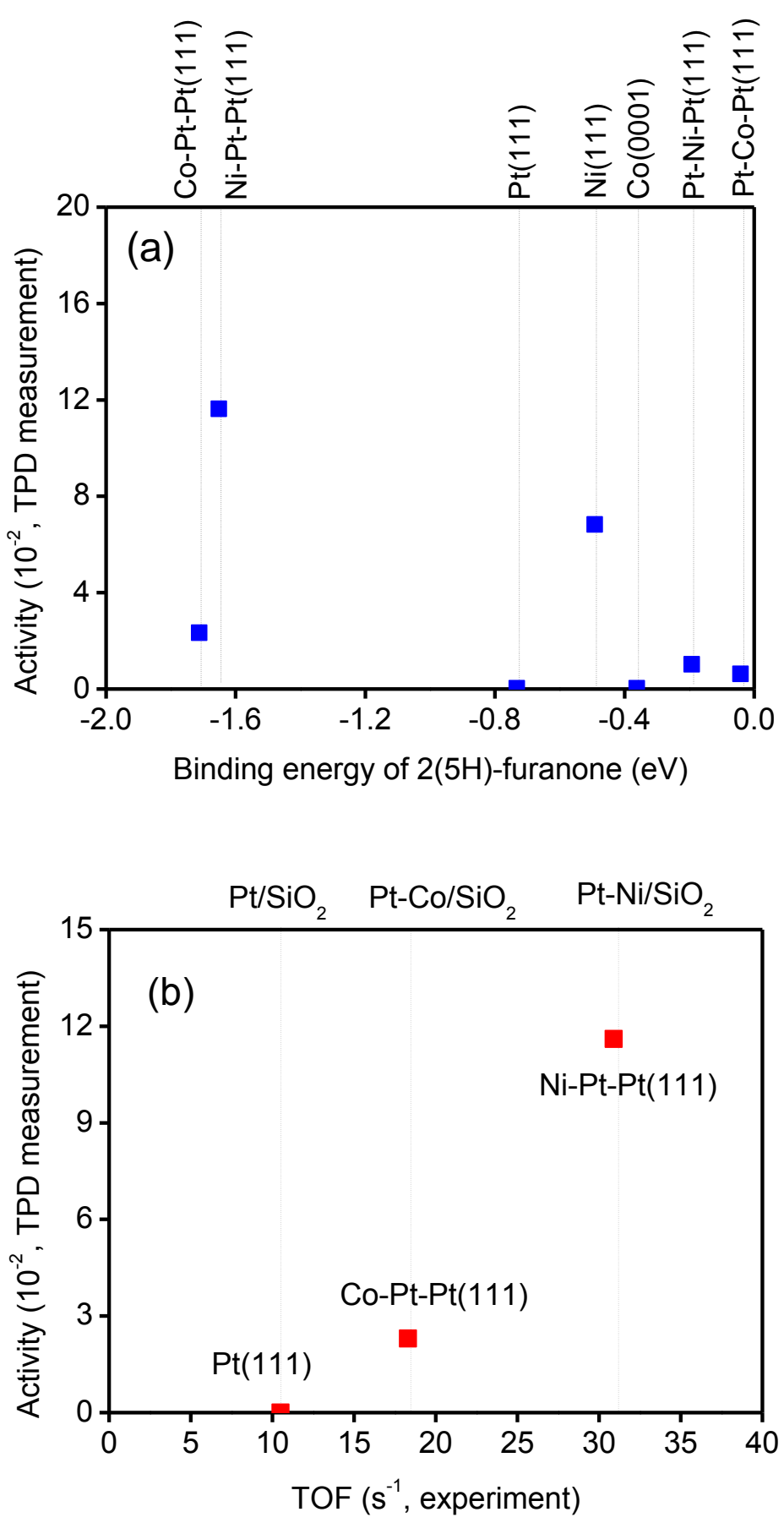

Fig. 7 Hydrogenation activity of 2(5H)-furanone to GBL from TPD experiments $v s$ (a) DFT calculated binding energy of $2(5 \mathrm{H})$-furanone on model surfaces and (b) TOF over the $\mathrm{SiO}_{2}$-supported catalysts. 


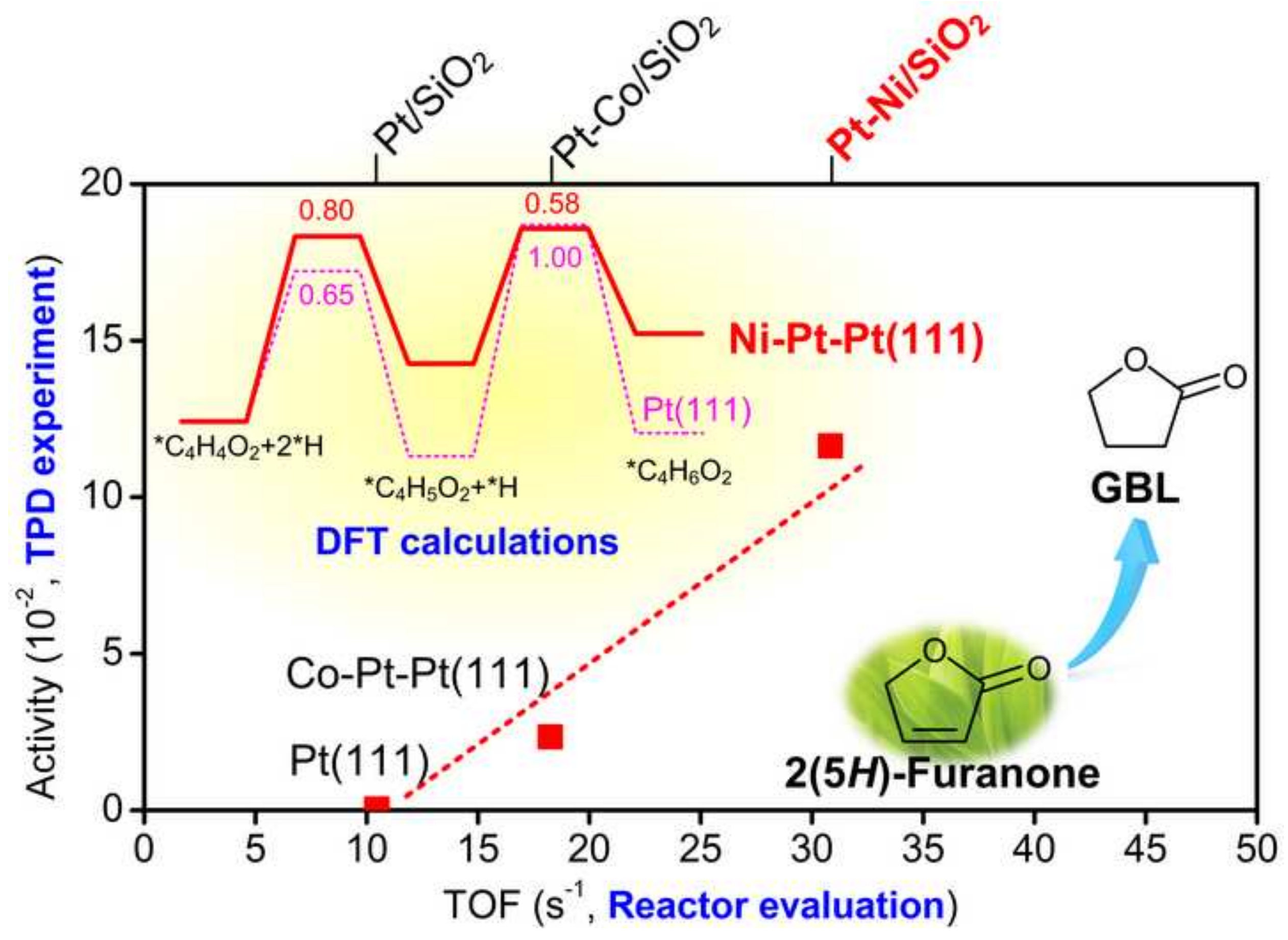

